\title{
Outcomes after suboccipital decompression without dural opening in children with Chiari malformation Type I
}

\author{
Benjamin C. Kennedy, MD, ${ }^{1}$ Kathleen M. Kelly, BA, ${ }^{1}$ Michelle Q. Phan, BS, ${ }^{1}$ Samuel S. Bruce, MA, ${ }^{1}$ \\ Michael M. McDowell, MD, ${ }^{2}$ Richard C. E. Anderson, MD, ${ }^{1,3}$ and Neil A. Feldstein, MD ${ }^{1,3}$ \\ 'Department of Neurological Surgery, Columbia University, New York, New York; ${ }^{2}$ Department of Neurological Surgery, Pittsburgh \\ University, Pittsburgh, Pennsylvania; and ${ }^{3}$ Children's Hospital of New York, Columbia University, New York, New York
}

\begin{abstract}
OBJECT Symptomatic pediatric Chiari malformation Type I (CM-I) is most often treated with posterior fossa decompression (PFD), but controversy exists over whether the dura needs to be opened during PFD. While dural opening as a part of PFD has been suggested to result in a higher rate of resolution of CM symptoms, it has also been shown to lead to more frequent complications. In this paper, the authors present the largest reported series of outcomes after PFD without dural opening surgery, as well as identify risk factors for recurrence.

METHODS The authors performed a retrospective review of 156 consecutive pediatric patients in whom the senior authors performed PFD without dural opening from 2003 to 2013. Patient demographics, clinical symptoms and signs, radiographic findings, intraoperative ultrasound results, and neuromonitoring findings were reviewed. Univariate and multivariate regression analyses were performed to determine risk factors for recurrence of symptoms and the need for reoperation.
\end{abstract}

RESULTS Over $90 \%$ of patients had a good clinical outcome, with improvement or resolution of their symptoms at last follow-up (mean 32 months). There were no major complications. The mean length of hospital stay was 2.0 days. In a multivariate regression model, partial C-2 laminectomy was an independent risk factor associated with reoperation $(p=$ $0.037)$. Motor weakness on presentation was also associated with reoperation but only with trend-level significance $(p=$ 0.075). No patient with $<8 \mathrm{~mm}$ of tonsillar herniation required reoperation.

CONCLUSIONS The vast majority (>90\%) of children with symptomatic CM-I will have improvement or resolution of symptoms after a PFD without dural opening. A non-dural opening approach avoids major complications. While no patient with tonsillar herniation $<8 \mathrm{~mm}$ required reoperation, children with tonsillar herniation at or below $\mathrm{C}-2$ have a higher risk for failure when this approach is used.

http://thejns.org/doi/abs/10.3171/2014.12.PEDS14487

KEY WORDS Chiari malformation; non-dural opening procedure; suboccipital decompression; duraplasty; outcomes

$\mathrm{C}$ HIARI malformation Type I (CM-I) is typically defined as descent of the cerebellar tonsils at least 5 $\mathrm{mm}$ below the foramen magnum. The incidence of the malformation is unknown but has been found in $0.78 \%$ of brain MRI scans. ${ }^{27}$

Posterior fossa decompression (PFD) for CM-I was first described in $1930^{30}$ and has continued to serve as the primary treatment for children and adults with symptoms referable to the malformation and severe enough to warrant surgical intervention. . $^{2,5-8,11-13,15,20,22,26,33,34,39,41}$
A variety of PFD methods with favorable outcomes have been described for pediatric CM-I. ${ }^{15,17,22,33}$ It is highly controversial whether the dura must be opened for adequate decompression, with surveys suggesting that $75 \%$ of pediatric neurosurgeons regularly open the dura, ${ }^{20,36,39}$ whereas others open the dura for a variety of clinical, radiographic, or intraoperative factors. ${ }^{6,26,28,33,36,47,48}$ Although pediatric neurosurgeons have a great deal of experience with PFD and duraplasty, both case series and intraoperative electrophysiological studies have demonstrated that

ABBREVIATIONS BAER = brainstem auditory evoked response; $\mathrm{CM}-\mathrm{I}=$ Chiari malformation Type I; PFD = posterior fossa decompression; SSEP = somatosensory evoked potential.

SUBMITTED September 18, 2014. ACCEPTED December 15, 2014.

INCLUDE WHEN CITING Published online May 1, 2015; DOI: 10.3171/2014.12.PEDS14487.

DISCLOSURE The authors report no conflict of interest concerning the materials or methods used in this study or the findings specified in this paper. 
in many patients physiological decompression can be achieved without opening of the dura. . $^{3,4,18,33,48}$

The primary purpose of this study was to review the outcomes of a large series of children with CM-I who underwent PFD without dural opening. A secondary goal was to try to identify patients who were at high risk for a recurrence of $\mathrm{CM}$ symptoms and need for reoperation after a PFD without dural opening.

\section{Methods}

Following approval by the Institutional Review Board at Columbia University Medical Center, we conducted a retrospective analysis of 156 patients under the age of 21 in whom the senior authors (N.A.F. and R.C.A.) performed CM-I decompression without dural opening from 2003 to 2013. Preoperative and postoperative records from office charts, operative reports, inpatient records, and pre- and postoperative imaging were reviewed. All patients had undergone MRI of the brain and the entire spinal cord.

Each patient underwent a bony decompression of the craniocervical junction without opening of the dura. Under general anesthesia, patients were placed in 3-point Mayfield fixation and turned into the prone position with moderate neck flexion. Neurophysiological monitoring of somatosensory evoked potentials (SSEPs) and brainstem auditory evoked responses (BAERs) was performed before (supine) and after (prone) positioning the patient and throughout the surgery. After standard surgical preparation, draping, and administration of antibiotics and local anesthesia, an incision was made from the inion to the upper cervical region. Subperiosteal dissection was performed to expose the occiput, foramen magnum, and C-1. A suboccipital craniectomy and C-1 laminectomy were then performed. The atlantooccipital ligament was then sharply incised, and numerous vertical scoring incisions were made in the outer layer of the cervical dura (Fig. 1).

Intraoperative ultrasound was used at this point to confirm that the decompression was adequate to reach the caudal aspect of the tonsils and ensure good pulsatility of the tonsils and CSF space ventral and dorsal to the tonsils. In 12 cases in which these findings could not be seen above C-2 on ultrasound, a partial laminectomy or undercutting of the superior lamina of C-2 was performed until these ultrasound findings were apparent. No patient underwent complete C-2 laminectomy. Meticulous hemostasis was then performed prior to multilayer closure with absorbable sutures.

Typically, patients spent the 1st postoperative night in the pediatric intensive care unit and were transferred to the floor the following day. Perioperative pain was usually managed with a combination of NSAIDs, opioids, and muscle relaxants.

Patients undergoing PFD for CM-I were excluded from the study and underwent a dural opening surgery as the initial procedure if any of the following conditions existed: 1) rapidly progressive neurological deficit (e.g., new onset of neurological deficit within 2 weeks, including motor weakness, sensory loss, or dysphagia); 2) rapidly progressive scoliosis (increase in maximum Cobb angle of greater than or equal to $25^{\circ}$ within 1 year) with a syrinx and presenting $\mathrm{Cobb}$ angle greater than $35^{\circ}$; 3) cerebellar

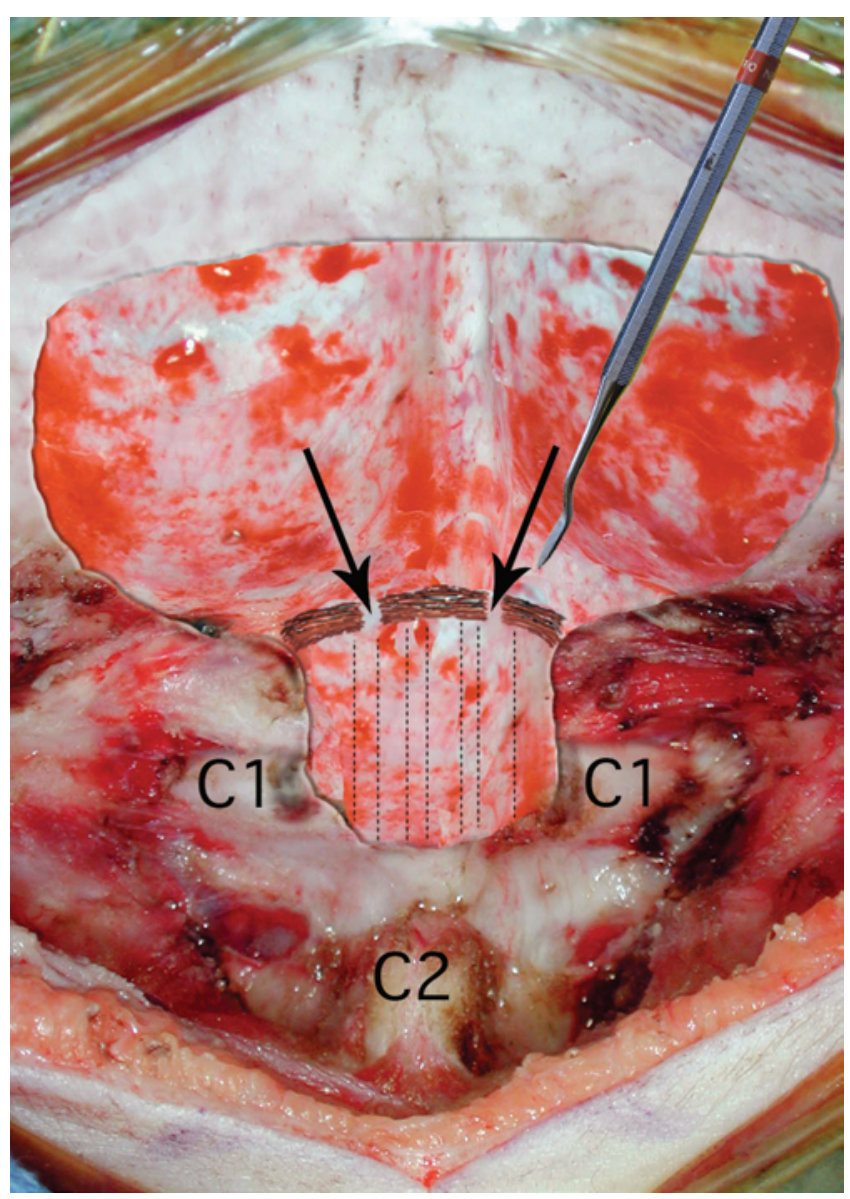

FIG. 1. Intraoperative photograph obtained after bony decompression, with overlaid illustration to indicate the general spatial orientation of the techniques of sectioning the atlantooccipital ligament (arrows) and the vertical scoring incisions in the outer layer of the dura (dashed lines), along with the instrument used for the vertical scoring incisions.

tonsillar descent below the bottom of the C-2 lamina on preoperative MRI; or 4) craniovertebral instability requiring posterior occipitocervical fusion at the time of the PFD (instability was investigated and diagnosed on a case-bycase basis when symptoms and radiological craniocervical abnormalities, such as basilar invagination, prompted relevant studies). In addition, patients were excluded from this analysis if they had previously undergone PFD at another institution or if they had an acquired, rather than congenital, CM.

Patients were followed as outpatients postoperatively. Clinical outcome was considered good if the patient remained asymptomatic or minimally symptomatic throughout the entire follow-up period. Minimally symptomatic was defined as persistence of subtle symptoms that did not affect the patient's return to school or routine activities. All patients who did not fit this criterion of good outcome underwent reoperation. Univariate and multivariate logistic regression modeling was used to assess the influence of a variety of factors on the need for reoperation. Univariate models were made for patient demographic factors, symptoms and signs at presentation, preoperative radiographic findings, and intraoperative ultrasound and neuromonitor- 
ing data. Any independent variable with a p value less than 0.2 was entered into a multivariate model. Significance in the multivariate model was determined by a p value of less than 0.05 , and a trend-level effect was assigned to a $p$ value between 0.05 and 0.10 . Four patients were lost to follow-up after discharge from the hospital, and these patients were included in analyses of presentation, intraoperative findings, and complication rate (156 patients reported), but not in analyses of resolution of symptoms or reoperation (152 patients reported) because these data were not available for those patients.

\section{Results \\ Patients}

One hundred fifty-six consecutive patients with CM-I were treated between 2003 and 2013 by the senior authors with suboccipital decompression without dural opening. Fifty-one percent (80/156) were boys, the mean age was 9.9 years (range 7 months to 20.6 years), and they presented with a mean symptom duration of 2.3 years. Four patients were lost to follow-up after discharge from the hospital, and the mean follow-up time for the other 152 patients with outpatient follow-up was 32 months.

\section{Presentation}

Headache and neck pain were the most common presenting signs or symptoms in communicative children, with irritability or atypical crying common among younger children (Table 1). Taken together, headache, neck pain, or irritability were present in $74 \%(116 / 156)$ of patients at presentation. Dysphagia, sensory deficits, and developmental delays were also common (Table 1). On examination, hyperreflexia was found in approximately one-third of patients (51/156 patients). The mean degree of tonsillar ectopia, as measured by the distance from the opisthion to the bottom of the lowest tonsil, was $12.3 \mathrm{~mm}$ (range 5-35 $\mathrm{mm})$. Forty-four percent (68/156) of patients had a syrinx apparent upon presentation; 51 involved cervical levels, 45 involved thoracic levels, and 9 had a holocord syrinx. Twelve patients with a syrinx were asymptomatic. Twelve percent (18/156) of patients had scoliosis, with a median Cobb angle of $25^{\circ}$. Four percent (7/156) of patients had hydrocephalus on presentation, 2 had tethered cords, 1 had neurofibromatosis Type 1 , and 3 had ventral compression caused by a retroflexed odontoid process.

\section{Intraoperative Findings}

All patients underwent intraoperative ultrasound to determine the adequacy of decompression after suboccipital decompression and C-1 laminectomy. In 92\% (144/156) of patients, this decompression appeared adequate because good pulsatile motion of the tonsils was noted with appreciable CSF space ventrally and dorsally. The other 12 patients did not demonstrate adequate decompression and therefore underwent undercutting of the rostral aspect of the C-2 lamina, after which good decompression and tonsillar motion was demonstrated in all 12 patients. In all 12 patients who underwent partial C-2 laminectomy, preoperative MRI had demonstrated tonsillar ectopia to the middle or bottom of the C-2 lamina.
TABLE 1. Signs and symptoms at presentation and last follow-up

\begin{tabular}{lcc}
\hline & \multicolumn{2}{c}{ No. of Patients } \\
\cline { 2 - 3 } \multicolumn{1}{c}{ Presenting Symptoms \& Signs } & $\begin{array}{c}\text { Preop } \\
\text { Finding }\end{array}$ & $\begin{array}{c}\text { Postop } \\
\text { Finding }\end{array}$ \\
\hline Occipital/tussive headache & 65 & 25 \\
\hline Neck pain & 56 & 23 \\
\hline Hyperreflexia & 51 & 8 \\
\hline Atypical headache & 50 & 37 \\
\hline Dysphagia & 40 & 6 \\
\hline Behavioral symptoms/developmental delay & 40 & 33 \\
\hline Sensory symptoms & 38 & 17 \\
\hline Irritability/crying & 28 & 7 \\
\hline Ataxia & 23 & 7 \\
\hline Back pain & 22 & 7 \\
\hline Motor weakness & 19 & 7 \\
\hline Asymmetric abdominal reflexes & 18 & 1 \\
\hline Snoring & 14 & 1 \\
\hline Apnea & 8 & 1 \\
\hline Nystagmus & 6 & 3 \\
\hline
\end{tabular}

Nearly all patients also had neuromonitoring of SSEPs and BAERs during surgery. Once a preoperative neck position was established in the prone position with SSEPs unchanged from baseline, there were no negative changes in the SSEPs during any patient's surgery. Seventy-eight percent $(121 / 156)$ of patients exhibited at least unilateral improvement in the wave I-V interpeak latency after bony decompression, with a mean improvement of 0.26 msec. The remaining 34 patients had stable BAERs throughout surgery.

\section{Complications}

There were no major complications or mortality. Three percent (4/156) of patients developed minor complications that consisted of 1 superficial wound infection, 1 perioperative thigh paresthesia that resolved, 1 uninfected stitch granuloma, and 1 perioperative pneumonia.

\section{Clinical Outcomes}

Ninety-one percent (138/152) of patients were asymptomatic or minimally symptomatic after surgery and throughout the follow-up period (mean 32 months), which was considered a good outcome. The mean and median lengths of stay were both 2.0 days. Thirty-eight percent (58/152) of patients were completely asymptomatic throughout the follow-up period, and 53\% (80/152) continued during the follow-up period with subtle, but improved, symptoms that did not affect their return to school or routine activities. All 14 patients (9\%) who did not remain asymptomatic or minimally symptomatic underwent reoperation for recurrence of CM symptoms or progression of scoliosis. Regarding specific symptoms, $62 \%(40 / 65)$ of patients who presented with occipital and/or tussive headache had complete resolution of headache. Similarly, 59\% (33/56) of those who presented with neck pain had complete resolution of neck pain (Table 1). The 12 patients who underwent surgery for an incidental syrinx remained asymptomatic. 


\section{Syrinx}

Forty-four percent (68/156) of patients presented with a syrinx. Postoperative MRI studies were available for review for 57 patients, whose mean radiographic followup duration was 32 months. Seventy percent (40/57) of patients demonstrated radiographic improvement, 23\% (13/57) remained stable, and 7\% (4/57) developed increased syrinx size or a new syrinx. Twelve percent $(8 / 68)$ of patients with a syrinx underwent reoperation for persistent or recurrent symptoms or progression of associated scoliosis (Tables 2 and 3). Of the 40 improved syringes, 13 (33\%) demonstrated near-complete collapse (Fig. 2) and $8(20 \%)$ were at least 50\% smaller. All 12 (100\%) incidentally discovered syringes improved radiographically postoperatively.

\section{Scoliosis}

Twelve percent (18/156) of patients presented with scoliosis, and 17 of these had an associated syrinx. Twentynine percent $(5 / 17)$ of the patients with syrinx-related scoliosis eventually underwent spinal fusion surgery. Of these 17 patients, 4 demonstrated improvement in scoliosis after non-dural opening decompression, all of whom had Cobb angles of $23^{\circ}$ or less upon presentation. Nine patients exhibited stable Cobb angles with an initial mean Cobb angle of $27^{\circ}$. Four patients had progression of their scoliosis, and this group presented originally with a mean Cobb angle of $29^{\circ}$. Two of the patients with progression (Patients 1 and 2 [Tables 2 and 3]) had a second PFD with dural opening, their scoliosis progressed further, and they proceeded to undergo spinal fusion. The remaining 2 patients underwent spinal fusion without further suboccipital decompression. One patient presented with moderate scoliosis, a large syrinx, and with snoring, back pain, and shoulder pain. Her symptoms resolved postoperatively, she remained asymptomatic throughout the follow-up period, and her syrinx demonstrated near-complete collapse. However, over the course of 3 years, her scoliosis progressed from a Cobb angle of $45^{\circ}$ to $65^{\circ}$. Repeated PFD was not offered because of her syrinx had collapsed and her symptoms had resolved, and she underwent spinal fusion. The other patient presented with a mild scoliosis, a large syrinx, and occipital headaches. His headaches rapidly improved postoperatively and remained improved. He was subsequently lost to follow-up and did not return until 9 years postoperatively when his Cobb angle had progressed from $21^{\circ}$ to $73^{\circ}$. At that point, repeated PFD was offered, but the family declined because the patient was headache free and the decision had already been made to proceed with spinal deformity surgery.

\section{Reoperation}

Ninety-one percent (138/152) of patients demonstrated complete or near-complete symptom resolution at last follow-up and did not require reoperation. No patient with less than $8 \mathrm{~mm}$ of tonsillar descent required reoperation.

Reoperation with a second PFD was performed in 9\% (14/152) of patients due to persistent, recurrent, or new Chiari symptoms (12/14) or progression of scoliosis without improvement of syrinx (2/14) (Tables 2 and 3). This
TABLE 2. Findings in the group of patients who underwent reoperation

\begin{tabular}{lc}
\hline \multicolumn{1}{c}{ Variable } & No. of Patients \\
\hline Total reoperated & 14 \\
\hline Primary rationale for 2nd surgery & 2 \\
\hline$\quad$ Progressive scoliosis & 4 \\
\hline Progressive symptomatic syrinx & 6 \\
\hline Return of CM symptoms & 2 \\
\hline New CM symptoms & 2 \\
\hline 2nd surgery & 1 \\
\hline Bony decompression only & 1 \\
\hline Non-dural opening for scar tissue & 10 \\
\hline Dural opening \& duraplasty only & \\
\hline Dural opening, tonsillar reduction, \& duraplasty &
\end{tabular}

group included all patients with worsening syrinx (3/68, $4 \%$ ) and one patient with new syrinx $(1 / 152,0.7 \%)$ (Tables 2 and 3). At the time of reoperation, 11 patients underwent dural opening with expansive duraplasty, including 10 who underwent tonsillar reduction. The remaining patient was assessed intraoperatively and considered to have adequate decompression without undergoing tonsillar reduction (Table 2). Two patients experienced regrowth of the suboccipital bone. Patient 8 was 13 months old at presentation, experienced a return of symptoms 14 months postoperatively, with bony regrowth noted on imaging, and had a good outcome after a second extradural bony decompression. Patient 9 was 19 months old at presentation and experienced a return of symptoms 9 months postoperatively, also with bony regrowth. He also had a good outcome after a second extradural bony decompression (Table 3 ). One other patient had constrictive epidural scarring and improved after repeat extradural surgery to remove and release this scarring. The mean age of patients who underwent reoperation was 8.6 years (range 1.1-19.9 years). Reoperations were conducted at a mean of 22 months after the first decompression (range 3-57 months), and reoperated patients were followed up for a mean of 49 months after the first surgery.

\section{Univariate and Multivariate Regression Models}

To identify risk factors for reoperation, the authors used univariate and multivariate modeling (Table 4). Of all the demographic variables, symptoms, signs, radiographic measurements, and intraoperative findings studied in univariate analyses, 4 factors reached the significance threshold for inclusion in the multivariate model $(\mathrm{p}<0.2)$ : $\mathrm{C}-2$ laminectomy $(p=0.001)$, degree of tonsillar ectopia $(p=$ $0.033)$, motor weakness $(p=0.07)$, and apnea $(p=0.138)$. Motor weakness was chronic in all cases because acute motor weakness would have led to dural opening surgery and exclusion from this cohort. Notably, the presence of a syrinx did not reach statistical significance $(\mathrm{p}=0.33)$.

When these 4 independent variables were entered into a multivariate model, C-2 laminectomy was the only statistically significant factor associated with reoperation $(\mathrm{OR} 6.22, \mathrm{p}=0.037)$. Motor weakness remained associ- 
TABLE 3. Summary of findings in individual patients who underwent reoperation

\begin{tabular}{|c|c|c|c|c|c|}
\hline $\begin{array}{l}\text { Patient } \\
\text { No. }\end{array}$ & Presentation & $\begin{array}{l}\text { Tonsillar } \\
\text { Descent } \\
(\mathrm{mm})\end{array}$ & $\begin{array}{c}\text { C-2 } \\
\text { Laminectomy }\end{array}$ & $\begin{array}{c}\text { Bony } \\
\text { Regrowth }\end{array}$ & Reason for Reoperation \\
\hline 1 & Syrinx, scoliosis, HA & - & & & Progressive scoliosis \\
\hline 2 & $\begin{array}{l}\text { Syrinx, scoliosis, dysphagia, neck } \\
\text { pain }\end{array}$ & 25 & Yes & & Progressive scoliosis \\
\hline 3 & $\begin{array}{l}\text { Syrinx, motor, sensory, ataxia, } \mathrm{HA} \text {, } \\
\text { neck pain }\end{array}$ & 8 & & & $\begin{array}{l}\text { Progressive syrinx after initial improvement \& } \\
\text { return of HA \& hand weakness }\end{array}$ \\
\hline 4 & Syrinx, motor, delay & 15 & & & $\begin{array}{l}\text { Progressive syrinx after initial improvement \& } \\
\text { persistent but improved developmental } \\
\text { delay }\end{array}$ \\
\hline 5 & Syrinx, back pain, neck pain & 22 & & & Progressive syrinx w/ new hand paresthesias \\
\hline 6 & Dysphagia, ataxia, $\mathrm{HA}$, neck pain & 10 & & & $\begin{array}{l}\text { New syrinx w/ improved but persistent } \mathrm{HA} \text {, in- } \\
\text { coordination, \& dysphagia }\end{array}$ \\
\hline 7 & Syrinx, sensory, HA, neck pain & 22 & & & $\begin{array}{l}\text { Return of LUE numbness \& new LUE weak- } \\
\text { ness }\end{array}$ \\
\hline 8 & Apnea, irritability & 16 & Yes & Yes & Return of apnea w/ new bradycardia \\
\hline 9 & Dysphagia, motor & 11.5 & & Yes & Return of HA \& dysphagia \\
\hline 10 & Apnea, motor, sensory, HA & 22 & Yes & & Return of HA \& neck pain \\
\hline 11 & Syrinx, sensory, HA & 10 & & & Return of neck pain \& hand paresthesias \\
\hline 12 & Ataxia, irritability, delay & 20 & Yes & & $\begin{array}{l}\text { Worsening of behavioral problems after initial } \\
\text { improvement }\end{array}$ \\
\hline 13 & Dysphagia, HA & 16.5 & Yes & & New BLE pain \& irritability \\
\hline 14 & $\begin{array}{l}\text { Syrinx, motor, sensory, neck pain, } \\
\text { delay }\end{array}$ & 13 & & & New dysphagia, ataxia, \& incontinence \\
\hline
\end{tabular}

BLE = bilateral lower extremity; HA = headache; LUE = left upper extremity; $-=$ not applicable.

ated with reoperation only at trend-level significance (OR $3.61, \mathrm{p}=0.075)$, whereas apnea $(\mathrm{OR} 2.56, \mathrm{p}=0.368)$ and degree of tonsillar ectopia (OR 1.03, p = 0.547) did not reach significance (Table 4).

\section{Discussion}

In this report of children presenting with symptomatic CM-I, we have demonstrated that PFD without dural opening results in a long-term success rate of over $90 \%$ with no major complications. To our knowledge, this is the largest reported series of posterior fossa decompressions without dural opening for pediatric Chiari I malformation.

Nearly $1 \%$ of brain MRI scans demonstrate radiographic CM-I, ${ }^{27}$ and approximately $20 \%$ of children with radiographic CM-I referred to a neurosurgeon require surgery. ${ }^{41}$ Evidence regarding the pathophysiology of the disease has not been conclusive, but the posterior fossae in CM-I patients have been found to be $23 \%$ smaller than those in controls. ${ }^{29,38,40,44}$ A small posterior fossa can result in cerebellar tonsillar herniation through the foramen magnum. Considering the mechanical nature of the disease process, it is generally accepted that surgical decompression is warranted for most symptomatic cases of CM-I.

The traditional technique for decompression involves suboccipital craniectomy with C-1 laminectomy, dural opening, and duraplasty. Some authors coagulate or resect the cerebellar tonsils in all or a subset of patients, and others advocate addressing the patency of the foramen of Magendie. . $^{1517,19,22,33,41,42}$ Proponents of dural opening contend that opening the dura increases the likelihood of symptom and syrinx improvement, although dural opening has been associated with higher complication rates.,11,12,17,19,20, 22,26,33,34,39

More recently, small case series of surgery without dural opening, mixed case studies, and a meta-analysis have

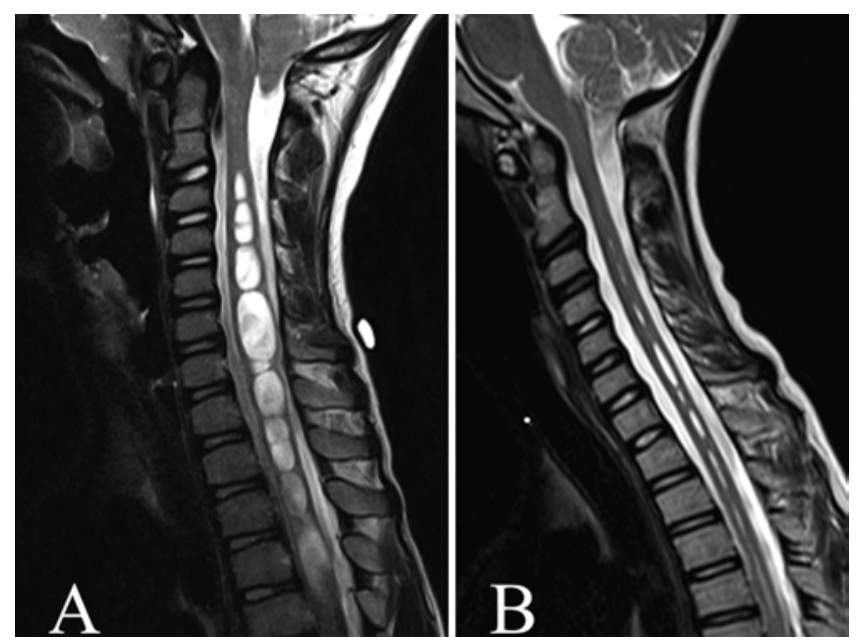

FIG. 2. A: Sagittal T2-weighted MRI scan of a 5-year-old boy who presented with a 1 -year history of a $16^{\circ}$ scoliosis with an associated cervicothoracic syrinx and CM-I with $14 \mathrm{~mm}$ of tonsillar ectopia. B: Sagittal T2-weighted MRI scan obtained 5 years after non-dural opening suboccipital decompression, showing near-complete collapse of the syrinx. The patient's scoliosis has stabilized. 
TABLE 4. Univariate and multivariate regression models of risk factors for reoperation

\begin{tabular}{|c|c|c|c|c|}
\hline \multirow[b]{2}{*}{ Independent Variable } & \multicolumn{2}{|c|}{ Univariate Model $^{*}$} & \multicolumn{2}{|c|}{ Multivariate Model† } \\
\hline & OR $(95 \% \mathrm{Cl})$ & $p$ Value & OR $(95 \% \mathrm{Cl})$ & p Value \\
\hline Male & $1.30(0.43-3.95)$ & 0.641 & & \\
\hline Preop syrinx & $1.73(0.57-5.26)$ & 0.333 & & \\
\hline Degree of tonsillar ectopia (mm) & $1.09(1.01-1.17)$ & 0.033 & $1.03(0.93-1.14)$ & 0.547 \\
\hline C-2 laminectomy & $9.03(2.45-33.32)$ & 0.001 & $6.22(1.13-34.27)$ & 0.037 \\
\hline Developed preop scoliosis & $1.27(0.26-6.20)$ & 0.767 & & \\
\hline Improved BAERs & $4.12(0.52-32.68)$ & 0.183 & & \\
\hline Age at surgery & $0.94(0.84-1.05)$ & 0.294 & & \\
\hline Symptom duration (yrs) & $0.97(0.91-1.03)$ & 0.27 & & \\
\hline Occipital HA & $0.72(0.23-2.27)$ & 0.578 & & \\
\hline Atypical HA & $1.19(0.38-3.75)$ & 0.771 & & \\
\hline Neck pain & $1.32(0.43-4.02)$ & 0.626 & & \\
\hline Irritability/crying & $1.36(0.35-5.28)$ & 0.654 & & \\
\hline Ataxia & $0(0-\operatorname{lnf})$ & 0.992 & & \\
\hline Nystagmus & $0(0-\operatorname{lnf})$ & 0.992 & & \\
\hline Dysphagia & $1.18(0.35-3.99)$ & 0.794 & & \\
\hline Apnea & $3.67(0.67-20.19)$ & 0.138 & $2.56(0.33-19.64)$ & 0.368 \\
\hline Snoring & $0.74(0.09-6.12)$ & 0.78 & & \\
\hline Motor weakness & $3.28(0.91-11.77)$ & 0.07 & $3.61(0.89-14.70)$ & 0.075 \\
\hline Sensory deficit & $0.80(0.21-3.04)$ & 0.747 & & \\
\hline Hyperreflexia & $1.04(0.57-1.89)$ & 0.895 & & \\
\hline Asymmetric abdominal reflexes & $1.04(0.55-1.96)$ & 0.9 & & \\
\hline Back pain & $0.74(0.14-3.96)$ & 0.728 & & \\
\hline Behavioral symptoms/developmental delays & $0.80(0.21-3.04)$ & 0.747 & & \\
\hline
\end{tabular}

reported that over $93 \%$ of patients exhibited symptomatic improvement, with reoperation rates of $7 \%-8 \% .8,11,18,19,33$ Using BAERs as a surrogate for physiological decompression, prior studies have shown intraoperative improvement after bony decompression with no further improvement after dural opening., ${ }^{3,48}$ Furthermore, surgery without dural opening has been associated with shorter operative time; shorter hospital stay; less use of narcotics, muscle relaxants, and antiemetics; and lower cost to patients and hospitals. . $^{16,23,24,32}$

Very few reports have compared the results of the two procedures, $17,23,24,31,33,45,47$ and there is no Level I or IIa evidence addressing this controversy. ${ }^{11,19}$ One large retrospective review of 256 patients identified surgery without dural opening as a risk factor for surgical failure, with a relative risk of 1.89, but after controlling for presenting symptoms, this effect was no longer present. ${ }^{25}$

Surveys in 1998 and 2004 each reported that $75 \%$ of pediatric neurosurgeons regularly open the dura, ${ }^{20,36,39}$ whereas other pediatric neurosurgeons have reported that they open the dura for a variety of clinical, radiographic, or intraoperative factors. ${ }^{6,26,28,33,36,47,48}$ At the 2006 American Society of Pediatric Neurosurgeons meeting, a survey of $50 \%$ of the membership demonstrated that for a symptomatic CM-I, only $6 \%$ of those surveyed would perform surgery without dural opening and another $6 \%$ would use ultrasound to guide the decision to add duraplasty, with the vast majority opting for duraplasty with or without tonsillar resection. When a syrinx was added to the hypothetical patient scenario, the non-dural opening and ultrasoundguided decision groups each fell to $4 \%$ of the surgeons. These results were observed despite the fact that almost all surgeons surveyed reported CSF-related complications as the most likely complication of surgery. ${ }^{36}$

Over $90 \%$ of patients in our study were asymptomatic or minimally symptomatic after surgery and throughout the follow-up period. This rate compares favorably to prior reports of improvement occurring in $83 \%$ in the largest series of dural opening surgeries ${ }^{41}$ and in $77 \%$ of patients reported in a recent meta-analysis of 582 patients undergoing dural opening surgery. ${ }^{11}$ Smaller series for both procedures, however, have reported higher rates of improvement. ${ }^{1,3,4,8,9,12,14,18,21,22,34}$

In the present study, there were no major complications. Minor complications occurred in $2.6 \%$ of patients, and these were not specific to CM surgery. The complication rates reported for dural opening surgery range from $0 \%$ to $40 \% .{ }^{1,3,4,9,12,14,21,22,33-35}$ In the largest series of pediatric dural opening surgeries of 500 patients, Tubbs and colleagues reported a low complication rate of $2.4 \% .{ }^{41}$ However, risks after dural opening surgery can be severe and include CSF leakage, bacterial meningitis, aseptic meningitis, increased 
bleeding, pseudomeningocele, and hydrocephalus, among others. Most large series have reported complication rates between $15 \%$ and $25 \%$ after dural opening procedures. This is in striking contrast to the complication rate after non-dural opening procedures, which is reported to range between $2 \%$ and $6 \%$. A recent meta-analysis, for example, reported a complication rate of $18.5 \%$ after dural opening surgery, whereas the complication rate was only $1.8 \%$ after non-dural opening surgery. Our study's finding are consistent with the literature and emphasize the markedly reduced rate and severity of complications associated with non-dural opening surgery.

Nine percent of the patients in our study required reoperation involving another PFD. This rate is slightly higher than the reoperation rate reported after most dural opening surgery, which is generally below 5\%., $19,22,25,34,41$ For example, the largest pediatric series of dural opening surgery reported a $3 \%$ reoperation rate, and a recent meta-analysis reported reoperation rates of $2.1 \%$ after dural opening versus $12.6 \%$ after non-dural opening surgery

It is clear from this and other studies that the vast majority of children with symptomatic CM-I will have a successful outcome after a suboccipital decompression without dural opening. However, some children require a dural opening procedure to achieve a good clinical outcome. In an attempt to identify risk factors for the need for reoperation after a non-dural opening surgery, we performed univariate and multivariate analyses using clinical and radiographic parameters. Our results demonstrated that partial C-2 laminectomy is associated with a $42 \%$ reoperation rate, which is much higher than the $6 \%$ reoperation rate for patients not undergoing partial C-2 laminectomy $(p=0.037)$. Each of these patients undergoing partial $C-2$ laminectomy demonstrated tonsillar descent to the middle or bottom of the C-2 lamina on preoperative MRI. In contrast, no patient with tonsillar descent of less than 8 $\mathrm{mm}$ required a reoperation. This finding is consistent with prior reports that have suggested that a higher degree of tonsillar ectopia may be associated with surgical failure in non-dural opening procedures. ${ }^{26}$

The presence of motor weakness at presentation increased the odds of requiring a reoperation to more than three times the odds for a patient without weakness, reaching trend-level significance (OR 3.61, p = 0.075). In one small study, syrinx-associated weakness was one of the symptoms most likely to improve, but it has not previously been identified as a predictor of outcome. ${ }^{6}$

The presence of any syrinx, including a holocord syrinx, at presentation was not associated with reoperation in our series. This finding is consistent with those of some reports but not others. ${ }^{18,33}$ Many surgeons routinely open the dura during PFD in patients with syringomyelia to address possible arachnoid adhesions obstructing outflow of the fourth ventricle. We believe that the frequency of intradural adhesions is low because we did not see this in any of the 68 syrinx patients in this study. In the 8 patients in this series who underwent reoperation for recurrent symptoms with syringomyelia, no arachnoid adhesions obstructing CSF flow were seen. During the follow-up period of just over 2.5 years, more $50 \%$ of the syringes in our series were less than half of their original size. Only 4 patients ( $7 \%$ of the patients with syringes and postoperative MRI available) had a syrinx that increased in size or one that newly developed. The range of pediatric patients who demonstrate syrinx improvement after dural opening is reported to be 55\%-100\%.1,3-6,12,21,22,34,43 Tubbs and colleagues have reported that $80 \%$ of syringes improved after the initial dural opening operation, and 95\% improved after a second operation. ${ }^{41} \mathrm{~A}$ meta-analysis by Durham and Fjeld-Olenec reported that $56 \%$ and $87 \%$ of patients experienced syrinx collapse after non-dural opening and dural opening procedures, respectively, but this difference was not statistically significant. ${ }^{11}$ However, it is important to note that syrinx collapse is not necessary for symptomatic improvement, $, 6,8,18,22,37,46$ and syringes may resolve in a delayed fashion. ${ }^{10}$

The present study is primarily limited by its retrospective nature, relatively short follow-up duration, lack of multicenter participation, and by the presence of some selection bias as described previously in the Methods. Nevertheless, to our knowledge, this study represents the largest reported series of children with CM-I undergoing PFD without dural opening. We have shown that after this procedure, greater than $90 \%$ of children will have an excellent outcome with no major complications and no reoperation. Children with less than $8 \mathrm{~mm}$ of tonsillar descent never required a reoperation, whereas those with tonsils that descended to the middle or bottom of the C-2 lamina had the highest risk for reoperation.

\section{Conclusions}

In our practice, we continue to recommend PFD without opening the dura for the vast majority of symptomatic patients with CM-I. We open the dura in patients with rapidly progressive neurological deficits, rapidly progressive scoliosis with syrinx, and craniovertebral instability requiring fusion. Based on the results of this study, we now recommend dural opening surgery if preoperative MRI suggests that partial C-2 laminectomy will be necessary to achieve adequate decompression of the tonsils. Pediatric neurosurgeons should consider a non-dural opening procedure for the majority of children with a symptomatic CM-I.

\section{References}

1. Alzate JC, Kothbauer KF, Jallo GI, Epstein FJ: Treatment of Chiari I malformation in patients with and without syringomyelia: a consecutive series of 66 cases. Neurosurg Focus 11(1):E3, 2001

2. Anderson NE, Willoughby EW, Wrightson P: The natural history and the influence of surgical treatment in syringomyelia. Acta Neurol Scand 71:472-479, 1985

3. Anderson RC, Dowling KC, Feldstein NA, Emerson RG: Chiari I malformation: potential role for intraoperative electrophysiologic monitoring. J Clin Neurophysiol 20:65-72, 2003

4. Anderson RC, Emerson RG, Dowling KC, Feldstein NA: Improvement in brainstem auditory evoked potentials after suboccipital decompression in patients with Chiari I malformations. J Neurosurg 98:459-464, 2003

5. Attenello FJ, McGirt MJ, Garcés-Ambrossi GL, Chaichana KL, Carson B, Jallo GI: Suboccipital decompression for Chiari I malformation: outcome comparison of duraplasty 
with expanded polytetrafluoroethylene dural substitute versus pericranial autograft. Childs Nerv Syst 25:183-190, 2009

6. Attenello FJ, McGirt MJ, Gathinji M, Datoo G, Atiba A, Weingart J, et al: Outcome of Chiari-associated syringomyelia after hindbrain decompression in children: analysis of 49 consecutive cases. Neurosurgery 62:1307-1313, 2008

7. Brockmeyer D, Gollogly S, Smith JT: Scoliosis associated with Chiari 1 malformations: the effect of suboccipital decompression on scoliosis curve progression: a preliminary study. Spine (Phila Pa 1976) 28:2505-2509, 2003

8. Caldarelli M, Novegno F, Vassimi L, Romani R, Tamburrini G, Di Rocco C: The role of limited posterior fossa craniectomy in the surgical treatment of Chiari malformation Type I: experience with a pediatric series. J Neurosurg 106 (3 Suppl):187-195, 2007

9. Danish SF, Samdani A, Hanna A, Storm P, Sutton L: Experience with acellular human dura and bovine collagen matrix for duraplasty after posterior fossa decompression for Chiari malformations. J Neurosurg 104 (1 Suppl):16-20, 2006

10. Doughty KE, Tubbs RS, Webb D, Oakes WJ: Delayed resolution of Chiari I-associated hydromyelia after posterior fossa decompression: case report and review of the literature. Neurosurgery 55:711, 2004

11. Durham SR, Fjeld-Olenec K: Comparison of posterior fossa decompression with and without duraplasty for the surgical treatment of Chiari malformation Type I in pediatric patients: a meta-analysis. J Neurosurg Pediatr 2:42-49, 2008

12. Ellenbogen RG, Armonda RA, Shaw DW, Winn HR: Toward a rational treatment of Chiari I malformation and syringomyelia. Neurosurg Focus 8(3):E6, 2000

13. Eule JM, Erickson MA, O'Brien MF, Handler M: Chiari I malformation associated with syringomyelia and scoliosis: a twenty-year review of surgical and nonsurgical treatment in a pediatric population. Spine (Phila Pa 1976) 27:1451-1455, 2002

14. Feldstein NA, Choudhri TF: Management of Chiari I malformations with holocord syringohydromyelia. Pediatr Neurosurg 31:143-149, 1999

15. Fischer EG: Posterior fossa decompression for Chiari I deformity, including resection of the cerebellar tonsils. Childs Nerv Syst 11:625-629, 1995

16. Foreman P, Safavi-Abbasi S, Talley MC, Boeckman L, Mapstone TB: Perioperative outcomes and complications associated with allogeneic duraplasty for the management of Chiari malformations Type I in 48 pediatric patients. J Neurosurg Pediatr 10:142-149, 2012

17. Galarza M, Sood S, Ham S: Relevance of surgical strategies for the management of pediatric Chiari type I malformation. Childs Nerv Syst 23:691-696, 2007

18. Genitori L, Peretta P, Nurisso C, Macinante L, Mussa F: Chiari type I anomalies in children and adolescents: minimally invasive management in a series of 53 cases. Childs Nerv Syst 16:707-718, 2000

19. Hankinson T, Tubbs RS, Wellons JC: Duraplasty or not? An evidence-based review of the pediatric Chiari I malformation. Childs Nerv Syst 27:35-40, 2011

20. Haroun RI, Guarnieri M, Meadow JJ, Kraut M, Carson BS: Current opinions for the treatment of syringomyelia and Chiari malformations: survey of the Pediatric Section of the American Association of Neurological Surgeons. Pediatr Neurosurg 33:311-317, 2000

21. Hoffman CE, Souweidane MM: Cerebrospinal fluid-related complications with autologous duraplasty and arachnoid sparing in type I Chiari malformation. Neurosurgery 62 (3 Suppl 1):156-161, 2008

22. Krieger MD, McComb JG, Levy ML: Toward a simpler surgical management of Chiari I malformation in a pediatric population. Pediatr Neurosurg 30:113-121, 1999

23. Limonadi FM, Selden NR: Dura-splitting decompression of the craniocervical junction: reduced operative time, hospital stay, and cost with equivalent early outcome. J Neurosurg 101 (2 Suppl):184-188, 2004

24. Litvack ZN, Lindsay RA, Selden NR: Dura splitting decompression for Chiari I malformation in pediatric patients: clinical outcomes, healthcare costs, and resource utilization. Neurosurgery 72:922-929, 2013

25. McGirt MJ, Attenello FJ, Atiba A, Garces-Ambrossi G, Datoo G, Weingart JD, et al: Symptom recurrence after suboccipital decompression for pediatric Chiari I malformation: analysis of 256 consecutive cases. Childs Nerv Syst 24:1333-1339, 2008

26. McGirt MJ, Attenello FJ, Datoo G, Gathinji M, Atiba A, Weingart JD, et al: Intraoperative ultrasonography as a guide to patient selection for duraplasty after suboccipital decompression in children with Chiari malformation Type I. J Neurosurg Pediatr 2:52-57, 2008

27. Meadows J, Kraut M, Guarnieri M, Haroun RI, Carson BS: Asymptomatic Chiari Type I malformations identified on magnetic resonance imaging. J Neurosurg 92:920-926, 2000

28. Milhorat TH, Bolognese PA: Tailored operative technique for Chiari type I malformation using intraoperative color Doppler ultrasonography. Neurosurgery 53:899-906, 2003

29. Milhorat TH, Chou MW, Trinidad EM, Kula RW, Mandell $\mathrm{M}$, Wolpert C, et al: Chiari I malformation redefined: clinical and radiographic findings for 364 symptomatic patients. Neurosurgery 44:1005-1017, 1999

30. Mortazavi MM, Tubbs RS, Hankinson TC, Pugh JA, CohenGadol AA, Oakes WJ: The first posterior fossa decompression for Chiari malformation: the contributions of Cornelis Joachimus van Houweninge Graftdijk and a review of the infancy of "Chiari decompression." Childs Nerv Syst 27:1851-1856, 2011

31. Munshi I, Frim D, Stine-Reyes R, Weir BK, Hekmatpanah J, Brown F: Effects of posterior fossa decompression with and without duraplasty on Chiari malformation-associated hydromyelia. Neurosurgery 46:1384-1390, 2000

32. Mutchnick IS, Janjua RM, Moeller K, Moriarty TM: Decompression of Chiari malformation with and without duraplasty: morbidity versus recurrence. J Neurosurg Pediatr 5:474478,2010

33. Navarro R, Olavarria G, Seshadri R, Gonzales-Portillo G, McLone DG, Tomita T: Surgical results of posterior fossa decompression for patients with Chiari I malformation. Childs Nerv Syst 20:349-356, 2004

34. Park JK, Gleason PL, Madsen JR, Goumnerova LC, Scott RM: Presentation and management of Chiari I malformation in children. Pediatr Neurosurg 26:190-196, 1997

35. Parker SR, Harris P, Cummings TJ, George T, Fuchs H, Grant G: Complications following decompression of Chiari malformation Type I in children: dural graft or sealant? J Neurosurg Pediatr 8:177-183, 2011

36. Rocque BG, George TM, Kestle J, Iskandar BJ: Treatment practices for Chiari malformation type I with syringomyelia: results of a survey of the American Society of Pediatric Neurosurgeons. J Neurosurg Pediatr 8:430-437, 2011

37. Sakamoto H, Nishikawa M, Hakuba A, Yasui T, Kitano S, Nakanishi N, et al: Expansive suboccipital cranioplasty for the treatment of syringomyelia associated with Chiari malformation. Acta Neurochir (Wien) 141:949-961, 1999

38. Schady W, Metcalfe RA, Butler P: The incidence of craniocervical bony anomalies in the adult Chiari malformation. $\mathbf{J}$ Neurol Sci 82:193-203, 1987

39. Schijman E, Steinbok P: International survey on the management of Chiari I malformation and syringomyelia. Childs Nerv Syst 20:341-348, 2004

40. Trigylidas T, Baronia B, Vassilyadi M, Ventureyra EC: Posterior fossa dimension and volume estimates in pediatric 
patients with Chiari I malformations. Childs Nerv Syst 24:329-336, 2008

41. Tubbs RS, Beckman J, Naftel RP, Chern JJ, Wellons JC III, Rozzelle CJ, et al: Institutional experience with 500 cases of surgically treated pediatric Chiari malformation Type I. J Neurosurg Pediatr 7:248-256, 2011

42. Tubbs RS, Smyth MD, Wellons JC III, Oakes WJ: Arachnoid veils and the Chiari I malformation. J Neurosurg 100 (5 Suppl Pediatrics):465-467, 2004

43. Valentini L, Visintini S, Saletti V, Chiapparini L, Estienne M, Solero CL: Treatment for Chiari 1 malformation (CIM): analysis of a pediatric surgical series. Neurol Sci 32 (Suppl 3):S321-S324, 2011

44. Vega A, Quintana F, Berciano J: Basichondrocranium anomalies in adult Chiari type I malformation: a morphometric study. J Neurol Sci 99:137-145, 1990

45. Ventureyra EC, Aziz HA, Vassilyadi M: The role of cine flow MRI in children with Chiari I malformation. Childs Nerv Syst 19:109-113, 2003

46. Wetjen NM, Heiss JD, Oldfield EH: Time course of syringomyelia resolution following decompression of Chiari malformation Type I. J Neurosurg Pediatr 1:118-123, 2008

47. Yeh DD, Koch B, Crone KR: Intraoperative ultrasonography used to determine the extent of surgery necessary during posterior fossa decompression in children with Chiari malformation type I. J Neurosurg 105 (1 Suppl):26-32, 2006

48. Zamel K, Galloway G, Kosnik EJ, Raslan M, Adeli A: Intra- operative neurophysiologic monitoring in 80 patients with Chiari I malformation: role of duraplasty. J Clin Neurophysiol 26:70-75, 2009

\section{Author Contributions}

Conception and design: Kennedy, Anderson, Feldstein. Acquisition of data: Kennedy, Kelly, Phan, McDowell, Anderson, Feldstein. Analysis and interpretation of data: Kennedy, Kelly, Phan, Bruce, Anderson, Feldstein. Drafting the article: Kennedy, Anderson, Feldstein. Critically revising the article: Kennedy, Bruce, Anderson, Feldstein. Reviewed submitted version of manuscript: all authors. Approved the final version of the manuscript on behalf of all authors: Kennedy. Statistical analysis: Kennedy, Bruce. Administrative/technical/material support: Anderson, Feldstein. Study supervision: Anderson, Feldstein.

\section{Supplemental Information}

\section{Previous Presentation}

The current work was presented at the AANS/CNS Joint Section on Pediatric Neurosurgery Annual Meeting, 2014.

\section{Correspondence}

Benjamin C. Kennedy, The Neurological Institute, 710 W. 168th St., 4th Fl., New York, NY 10032. email: benjamin.c.kennedy@ gmail.com. 